\title{
Comprehensive Study for Impure and Pure Casts of Aluminum and Copper
}

Raiq Rafi Omar Al-Nima*, Mahmood Ahmed Hmood Al-jiboori
Department of Physics, College of Science, University of Mosul, Mosul, Iraq

*Correspondence: raiq.scp83@student.uomosul.edu.iq

\begin{abstract}
Impure and pure casts have collected reasonable attentions over all the world. In this paper, Aluminum $(\mathrm{Al})$ and Copper $(\mathrm{Cu})$ cast alloys are considered to be studied. Multiple impure and pure Al-Cu cast alloys are established under the condition of very high temperatures. Then, all of the established alloys are examined by applying mechanical tests. More specifically, tests of hardness are exploited. Moreover, different quenching conditions are employed and analyzed. These are the water, air and oil. Consistent results are separately obtained for the impure and pure materials.
\end{abstract}

Key words: Casts, Aluminum, Copper, Mechanical Tests

\section{Introduction}

Cast alloys are essential materials that can be used in many fields. For example, manufacturing cars, trains, airplanes and trunks. A cast alloy refers to a mixed metal between two or more elements, where various ratios of elements are melted and combined to produce the certain alloy. The resulted cast alloy has different specifications that are completely different from essential characteristics of each component element. The cast alloys can be made by a combination between two or more elements of Aluminium (Al), Copper (Cu), Zinc (Zn), Magnesium (Mg), Manganese (Mn), Silicon (Si) and others [1]. Fig. 1 shows examples of various cast alloys. 

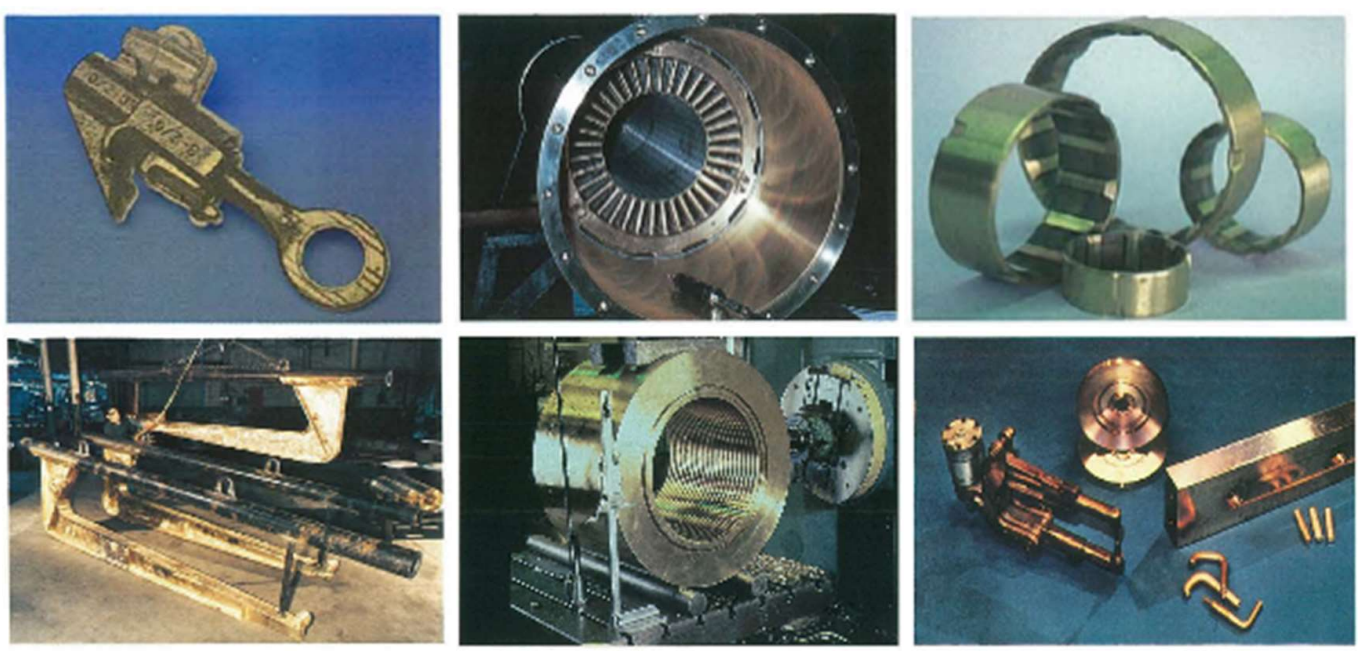

Figure 1: Examples of various cast alloys as provided in [2]

$\mathrm{Al}$ is reported as one of the most important elements. It abundant metal in the earth where it constructs about $8 \%$ of weighted solid earth surface. It generally uses in many purposes due to its weight ratio, good corrosion resistance, low density, good formability, high strength stiffness and recycling potential [3]. It has a Face Center Cubic (FCC) crystal structure and its ductility is taken at a very low temperature of approximately $660^{\circ} \mathrm{C}$ (or $\left.1120^{\circ} \mathrm{F}\right)[4][5]$. The $\mathrm{Cu}$ element is the most common series element. Its importance directly comes after the elements of gold, silver and platinum. It also has the same FCC crystal structure of $\mathrm{Al}$ and it is melted in $1080^{\circ} \mathrm{C}[2][6]$.

Combining between the $\mathrm{Al}$ and $\mathrm{Cu}$ can provide such interesting cast alloys. That is, their cast alloys may have significant mechanical properties such as hardness and high strength, and good machinability [7]. They are used in some important manufacturer such as bus bodies, beverage cans and automotive parts [1]. Al-Cu chain alloys can be utilized for the machine parts, aircraft materials and structural materials. Significant characteristics of high damage tolerance, high strength to weight ratio, cutting properties and good fatigue resistance are resulted [6]. 
The aim of this paper is preparing cast alloys of impure and pure Al-Cu. Then, testing some important mechanical properties such as hardness. The advantages of this work can be exploited in very critical industries, for instance, manufacturing ships and airplanes.

The remaining sections after the introduction are organized as follows: Section 2 provides the related literature review, Section 3 illustrates the theoretical part of this study, Section 4 demonstrates the practical results and Section 5 clarifies the conclusion.

\section{Related Literature Review}

Many studies were presented for the Al-Cu cast alloys. In 2006, Wang et al. introduced a work for the Al-Cu-Mg alloys. Precipitation hardening was employed to be investigated. Differential Scanning Calorimetry (DSC) and Transmission Electron Microscopy (TEM) were applied [8]. In 2008, An et al. studied the utilizable ductility and high strength for the bulk ultrafine-grained of $\mathrm{Cu}-\mathrm{Al}$ alloys. It was clarified that for providing engineering materials with high perfect ductility and strength hardness could be considered as a continuous challenging task for material scientists to satisfy different structural purposes [9]. In 2010, Min et al. explored the influence of returning the mechanical and microstructure characteristics of $\mathrm{Al}-\mathrm{Cu}$ alloys. Conditions of heating and casting treatments were concentrated in order to attain the returns optimum quantity which might be added to the Al-Cu alloys [10]. In 2011, An et al. described the effects on the mechanical characteristics, by focusing on the Stacking Fault Energy (SFE). Nanostructured $\mathrm{Cu}$ and $\mathrm{Cu}-\mathrm{Al}$ alloys were treated under a high-pressure condition [11]. In 2012, Hao et al. provided a work on the SFE. Compression Testing effects were considered for the $\mathrm{Cu}$ and $\mathrm{Cu}-\mathrm{Al}$ Alloys. Deformation of twinning $\mathrm{Cu}-\mathrm{Al}$ alloys was 
studied. Furthermore, the SFE plasticity, dynamic recovery and strength were analyzed for the $\mathrm{Cu}-\mathrm{Al}$ alloys [12]. In the same year, Ayoola et al. investigated the influence of casting mould. Al alloy for the type of 6063 was utilized. Multiple mechanical characteristics were exploited such as metal mould, naturally-bonded sand mould and cement-bonded sand mould [13]. In 2016, Belov et al. presented theoretical and practical work for a range of $\mathrm{Al}$ alloys. Group of elements were used, these are the $\mathrm{Al}$, $\mathrm{Cu}$, Si and Tin (Sn). So, the $\mathrm{Al}$ and $\mathrm{Cu}$ alloys were parts of this study [14]. In the same year, Madhusudan et al. concentrated on the mechanical characteristics of $\mathrm{Al}$ and $\mathrm{Cu}$ elements. They both were taken as Composite Metallic Materials (CMMs). Hardness, microstructures and changing the $\mathrm{Cu}$ concentrations were carried out for the $\mathrm{Al}-\mathrm{Cu}$ alloys [15]. In 2017, Stošića et al. utilized three elements of Al, $\mathrm{Cu}$ and $\mathrm{Zn}$ in alloys. Thermal and composition and treatments were provided. Shape-memory characteristics was analyzed [16]. In the same year, Bansal et al. exploited three elements of $\mathrm{Al}, \mathrm{Cu}$ and $\mathrm{Mg}$. Characterization and Synthesis of Al-Cu-Mg alloys were illustrated. Aging and deformation influences were studied on the characteristics of employed alloys [17]. In 2018, Bozorgi and Anders used cast alloys of the elements Al, Cu and Si. Mechanical characteristics were undertaken for the high $\mathrm{Cu}$ at elevated temperature. The $\mathrm{Al}-\mathrm{Cu}-\mathrm{Si}$ alloys were examined without including other expensive element such as Cerium (Ce), Cobalt (Co) and Silver (Ag) [18]. In 2019, Su and Young work with the material characteristics of high strength and normal Al alloys. Al alloys for the types of 6063-T5 and 6061-T6 were employed. Elevated temperatures were applied [19]. In the same year, Wang et al. considered multiple observations for a specific $\mathrm{Al}-\mathrm{Cu}-\mathrm{Zn}-\mathrm{Mg}$ alloy. These observations are for the mechanical characteristics, corrosion manner and microstructure. Non-Isothermal Ageing (NIA) treatment was adopted [7]. In 2020, Soni and Mandloi 
explained tribological and mechanical properties of artificial age. The Al-Zn-Mg-Cu alloy was concentrated. Various aging temperatures were examined with the precipitation kinetics to enhance the tribological and mechanical characteristics. That is, over aging, optimum aging, under aging and pre aging were used [20]. Also in the same year, Puga illustrated forming and casting of advanced Al alloys. It has been highlighted that the competitiveness and quality of a casting are strongly based on the technique that is used to generate it and quality of the molten alloy. Furthermore, it has been cited that casting the $\mathrm{Al}$ alloy is a difficult process as it is prone to heterogeneous and dendritic structures, in addition to the hydrogen absorption during melting [21].

From the literature it can be noticed that many work were applied for Al alloys, as well as, for $\mathrm{Cu}$ alloys. However, they are still requiring more investigations. In this paper, comprehensive study is provided for impure and pure Al-Cu cast alloys by establishing many samples and applying effective treatments.

\section{Theoretical Part}

In this work, extensive processes are considered, each of which has reasonable theory. Fig. 2 shows the general block diagram of these extensive processes.

It consists of multiple steps. Firstly, collecting the materials of $\mathrm{Al}$ and $\mathrm{Cu}$ in their two categories: impure and pure. The impure $\mathrm{Al}$ and $\mathrm{Cu}$ have been acquired from recycled and wasted materials, this may benefits in recycling and cleaning environment. On the other hand, the pure $\mathrm{AL}$ and $\mathrm{Cu}$ have been purchased as $\mathrm{Al}$ saturation of $98 \%$ and $\mathrm{Cu}$ saturation of $99 \%$. Secondly, grouping both the $\mathrm{Al}$ and $\mathrm{Cu}$ into two groups of impure and pure, where each group is separately processed. Thirdly, changing percentages of weights are applied for the $\mathrm{Al}$ and $\mathrm{Cu}$. Table 1 shows the prepared weights and ratios for the 
impure $\mathrm{Al}$ and $\mathrm{Cu}$. Whereas, Table 2 provides the employed weights and ratios for the pure $\mathrm{Al}$ and $\mathrm{Cu}$.

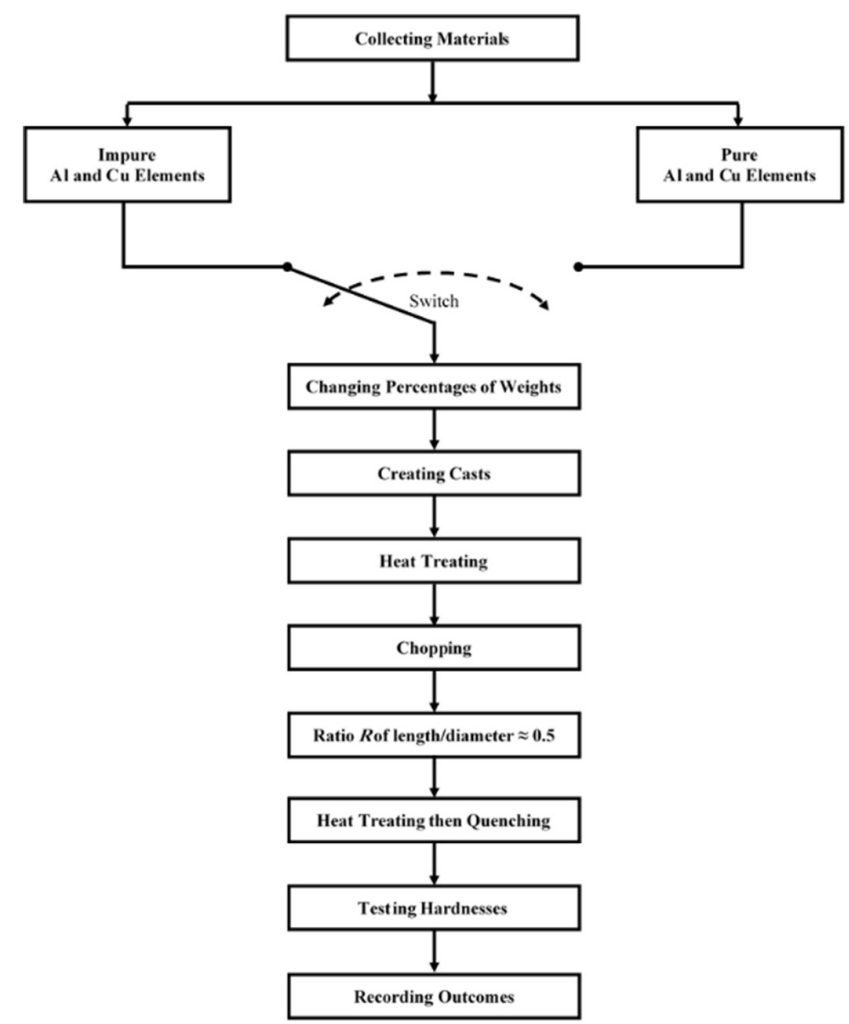

Figure 2: The general block diagram of the applied extensive processes

Table 1: The prepared weights and ratios for the impure $\mathrm{Al}$ and $\mathrm{Cu}$

\begin{tabular}{|c|c|c|c|c|}
\hline Index & $\mathbf{A l}(\mathbf{g m})$ & $\mathbf{C u}(\mathbf{g m})$ & $\mathbf{A l}(\mathbf{\%})$ & $\mathbf{C u}(\%)$ \\
\hline 1 & 15 & 10 & 60 & 40 \\
\hline 2 & 16.25 & 8.75 & 65 & 35 \\
\hline 3 & 16.75 & 8.25 & 67 & 33 \\
\hline 4 & 17.5 & 7.5 & 70 & 30 \\
\hline 5 & 18.75 & 6.25 & 75 & 25 \\
\hline 6 & 25 & 0 & 100 & 0 \\
\hline 7 & 0 & 25 & 0 & 100 \\
\hline
\end{tabular}

Table 2: The employed weights and ratios for the pure $\mathrm{Al}$ and $\mathrm{Cu}$

\begin{tabular}{|c|c|c|c|c|}
\hline Index & $\mathbf{A l}(\mathbf{g m})$ & $\mathbf{C u}(\mathbf{g m})$ & $\mathbf{A l}(\mathbf{\%})$ & $\mathbf{C u}(\mathbf{\%})$ \\
\hline 1 & 15 & 10 & 60 & 40 \\
\hline 2 & 16.25 & 8.75 & 65 & 35 \\
\hline 3 & 16.75 & 8.25 & 67 & 33 \\
\hline 4 & 17.5 & 7.5 & 70 & 30 \\
\hline 5 & 18.75 & 6.25 & 75 & 25 \\
\hline 6 & 25 & 0 & 100 & 0 \\
\hline
\end{tabular}


4. Fourthly, establishing multiple cast alloys between the $\mathrm{Al}$ and $\mathrm{Cu}$ according to the exploited weight ratios that are given in Tables 1 and 2. Each cast alloy has been prepared by applying very high temperature to melt the $\mathrm{Al}$ and $\mathrm{Cu}$. With more illustration, the $\mathrm{Cu}$ has been melted under the high temperature in a gas furnace, then, the Al has been added and mixed to the $\mathrm{Cu}$ in the same gas furnace. So, both are melted and carefully mixed together until being homogenous where a cast alloy of Al-Cu is finally established. These processes have been repeated many times where different cast alloys of $\mathrm{Al}-\mathrm{Cu}$ are acquired. Fifthly, the cast alloys are treated by heating inside an electric furnace to operate concretions. Consequently, the cast alloys are stayed inside the electric furnace after turning it off for about one day. Sixthly, acquired cast alloys are chopped. Seventhly, a cutting ratio $(R)$ is considered by rubbing each cast alloy, where: $R$ is define as length divided by diameter. In this study, the cutting ratio is taken as $R \approx 0.5$. Eighthly, heat treating is used once more again for the cast alloys inside the electric furnace (with 1 hour at $500^{\circ} \mathrm{C}$ ) to examine different quenching conditions. Subsequently, treated cast alloys are quenched by oil, water or air. Ninthly, the measurements of hardness are applied. Hardness measurement method of Vickers Hardness (HV) is utilized according to the following equation [22]:

$H V_{N}=\frac{2 P \sin \left(\frac{\emptyset}{2}\right)}{D_{\text {mean }}^{2}}=1.854 \frac{P}{D_{\text {mean }}^{2}}$

where: $H V_{N}$ is the HV measurement for $N$ number, $P$ is the load in $(\mathrm{Kg}), \emptyset=136^{\circ}$, $\sin \left(\frac{\emptyset}{2}\right)=0.927$ and $D_{\text {mean }}^{2}$ is the squared average between the length and width of pressured diamond head. 
Furthermore, additional hardness measurements are computed. These are the Hardness Brunel (HB) and Tensile Strength (TS). HB measurement has been collected from the Hardness Conversion Table (HCT) [22]. TS measurement can simply be calculated as follows [22]:

$T S_{N}=3.45 \times H B_{N}$

where: $T S_{N}$ is the TS measurement for $N$ number and $H B_{N}$ is the H.B measurement for $N$ number.

It is worth mentioning that the eutectic point, two nearest points around it and two far points of hypoeutectoid and hypereutectoid have been considered in this study. The eutectic point is defined as a smallest measured point that refers to easy melt of casted elements. Furthermore, the hypoeutectoid and hypereutectoid points are denoted as the measured points which positioned in locations less and high than the eutectic point, respectively [22].

Finally, outcomes of the employed measurements for established cast alloys are recorded and compared.

\section{Practical Part with Discussions}

First of all, multiple $\mathrm{Al}-\mathrm{Cu}$ cast alloys have been established. In each alloy a $\mathrm{Cu}$ was firstly melted under very high temperatures by using a gas furnace. Consequently, the Al was secondly added to the melted $\mathrm{Cu}$ in the same gas furnace. So, the Al was gradually melted too. Both were carefully mixed by using a rod of Carbon (C). Then, the mixed liquid was spilled into a mold of steel and concreted. These processes were repeated many times where 13 samples of Al-Cu cast alloys have been created. 
The established samples are divided into two main groups (impure and pure). The impure group consists of 7 samples for various $\mathrm{Al}$ and $\mathrm{Cu}$ percentages of weights ${ }^{(1)}$. On the other hand, the pure group consists of 6 samples for various $\mathrm{Al}$ and $\mathrm{Cu}$ percentages of weights too. The prepared weights and ratios for the impure $\mathrm{Al}$ and $\mathrm{Cu}$ are given in Table 1 . Whilst, the prepared weights and ratios for the pure $\mathrm{Al}$ and $\mathrm{Cu}$ are given in Table 2.

The created cast alloys have been treated by heating for the $1^{\text {st }}$ time in order to operate recrystallization, where an electric furnace was used. The established cast alloys were spent an 1 hour at high temperature of $500^{\circ} \mathrm{C}$. Subsequently, the electric furnace was turned off and the cast alloys were left inside for around 24 hours. Then, the established cast alloys have been chopped with a $R$ of rubbing that approximately equal to 0.5 . Each sample has been carefully covered and labeled. Fig. 3 shows examples of these samples. Heat treating has been applied for the $2^{\text {nd }}$ time in order to examine different quenching conditions, where the same electric furnace was utilized. Similar time and temperature treatments $\left(1\right.$ hour at $\left.500^{\circ} \mathrm{C}\right)$ were employed. The difference between the $1^{\text {st }}$ and $2^{\text {nd }}$ times of heat treating is that the $2^{\text {nd }}$ time did not consider leaving the created cast alloys inside the electric furnace for about 24 hours. However, they are quenched by oil, water or air. Hence, the hardness has been measured for all the established cast alloys. More specifically, the hardness measurements of $\mathrm{HV}, \mathrm{HB}$ and TS have been applied. For evaluating the $\mathrm{HV}$, the WOLPERT device of type (V-Testor 2 ) with $P=1 \mathrm{Kg}$ and Equation (1) have been exploited. For assessing the HB, the HCT [22] has been utilized. For computing the TS, Equation (2) has been employed. Tables 3 and 4 show the details and measurements of the $\mathrm{Al}-\mathrm{Cu}$ cast alloys for both impure and pure groups, respectively.

(1) Weight Percentage (wt\%) can be converted to Atomic weight Percentage (At\%). 
Figs. 4 and 5 demonstrate relationships between the $\mathrm{HV}$ measurements and $\mathrm{Cu}$ wights(100-Al wights) with the different quench types of the Al-Cu cast alloys for both impure and pure groups, respectively.

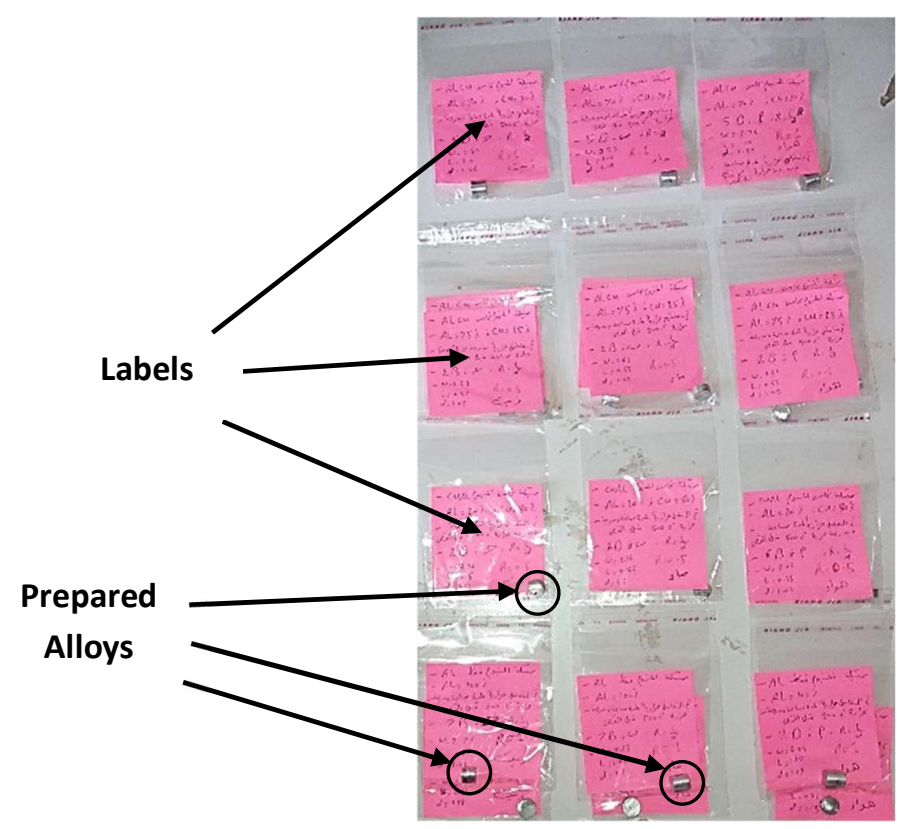

Figure 3: Examples of the established cast alloys, where each sample has been carefully covered and labeled

It can be seen that five main points have been assigned in this work, as mentioned. These are the eutectic point, two near points around it and two far points of hypoeutectoid and hypereutectoid.

First of all, the measured HV, HB and TS values for the impure cast alloys are more fluctuated than the pure cast alloys. This is due to the effects of other embedded elements in the impure cast alloys.

Reasonable outcomes can be observed from Table 3 and Fig. 4. That is, in all samples of the Al-Cu cast alloys impure group for the HV measurements to all quenched conditions, the eutectic point is located in the value when $\mathrm{Cu}$ weight is equal to $33 \%$. The hardness 
in this point can be considered as very low in all the measured cases. For the point that is positioned near from the eutectic in the value when $\mathrm{Cu}$ weight is equal to $30 \%$, the hardness in this point has attained the highest HV in all the measured cases. Likewise, these results are consistent with other employed measurements of HB and TS as shown in Table 3.

Interested outcomes can be investigated from Table 4 and Fig. 5. To illustrate, in all samples of the Al-Cu cast alloys pure group for the HV measurements to all quenched conditions, the eutectic point (when $\mathrm{Cu}$ weight is equal to $33 \%$ ) or a point near from it (when $\mathrm{Cu}$ weight is equal to $35 \%$ ) has obtained the highest HV. For the hypoeutectoid point that is positioned far from the eutectic in the value when $\mathrm{Cu}$ weight is equal to $0 \%$ and $\mathrm{Al}$ weight is equal to $100 \%$, the hardness in this point has attained the lowest $\mathrm{HV}$ in all the measured cases. Similarly, these results are consistent with other employed measurements of HB and TS as shown in Table 4.

The main difference between the impure and pure performance is that in the impure measurements the eutectic points have achieved low HV, HB and TS evaluations, whilst, in the pure measurements the eutectic points have achieved high $\mathrm{HV}, \mathrm{HB}$ and TS evaluations. This is reasonable as the performances of impure cast alloys are affected by other embedded elements. The results of pure measurements can be used as standards because no other embedded elements could influence the performances. 
Table 3: Details and measurements of the Al-Cu cast alloys impure group

\begin{tabular}{|c|c|c|c|c|c|c|}
\hline \multirow{2}{*}{ Quench Type } & \multirow{2}{*}{$\mathrm{Al}(\%)$} & \multirow{2}{*}{$\mathrm{Cu}(\%)$} & \multirow{2}{*}{$D_{\text {mean }}(\mathrm{mm})$} & \multicolumn{3}{|c|}{ Measurements } \\
\cline { 5 - 7 } & & & & $\mathrm{HV}(\mathrm{Kg} / \mathrm{mm} 2)$ & $\mathrm{HB}(\mathrm{Kg} / \mathrm{mm} 2)$ & $\mathrm{TS}(\mathrm{Mpa})$ \\
\hline Air & 60 & 40 & 0.085 & 256.6 & 244.28 & 842.76 \\
\hline Oil & 60 & 40 & 0.083 & 269.1 & 255.28 & 880.716 \\
\hline Water & 60 & 40 & 0.08 & 289.6 & 274.6 & 947.37 \\
\hline Air & 65 & 35 & 0.088 & 239.4 & 227.4 & 784.737 \\
\hline Oil & 65 & 35 & 0.083 & 269.1 & 255.2 & 880.7 \\
\hline Water & 65 & 35 & 0.08 & 289.6 & 274.6 & 947.37 \\
\hline Air & 67 & 33 & 0.158 & 74.2 & -- & - \\
\hline Oil & 67 & 33 & 0.15 & 82.4 & -- & - \\
\hline Water & 67 & 33 & 0.145 & 88.18 & 84.1 & 290.4 \\
\hline Air & 70 & 30 & 0.077 & 312.7 & 296.4 & 1022.6 \\
\hline Oil & 70 & 30 & 0.075 & 329.6 & 312.6 & 1078.4 \\
\hline Water & 70 & 30 & 0.072 & 357.6 & 338.6 & 1168.4 \\
\hline Air & 75 & 25 & 0.1 & 185.4 & 176.4 & 608.5 \\
\hline Oil & 75 & 25 & 0.095 & 205.4 & 195.4 & 674.1 \\
\hline Water & 75 & 25 & 0.09 & 228.8 & 217.8 & 751.4 \\
\hline Air & 100 & 0 & 0.122 & 124.5 & 118.5 & 408.8 \\
\hline Oil & 100 & 0 & 0.25 & 29.66 & -- & - \\
\hline Water & 100 & 0 & 0.114 & 142.6 & 135.6 & 467.8 \\
\hline Air & 0 & 100 & 0.153 & 79.2 & -- & - \\
\hline Oil & 0 & 100 & 0.122 & 147.7 & 140.7 & 485.4 \\
\hline Water & 0 & 100 & 0.11 & 153.2 & 145.8 & 503.01 \\
\hline & & & & & & \\
\hline
\end{tabular}

Table 4: Details and measurements of the $\mathrm{Al}-\mathrm{Cu}$ cast alloys pure group

\begin{tabular}{|c|c|c|c|c|c|c|}
\hline \multirow{2}{*}{ Quench Type } & \multirow{2}{*}{$\mathrm{Al}(\%)$} & \multirow{2}{*}{$\mathrm{Cu}(\%)$} & \multirow{2}{*}{$D_{\text {mean }}(\mathrm{mm})$} & \multicolumn{3}{|c|}{ Measurements } \\
\hline & & & & $\mathrm{HV}(\mathrm{Kg} / \mathrm{mm} 2)$ & $\mathrm{HB}(\mathrm{Kg} / \mathrm{mm} 2)$ & TS(Mpa) \\
\hline Air & 60 & 40 & 0.105 & 168.1 & 160.1 & 552.3 \\
\hline Oil & 60 & 40 & 0.099 & 189.1 & 180.1 & 621.5 \\
\hline Water & 60 & 40 & 0.095 & 205.4 & 195.4 & 674.1 \\
\hline Air & 65 & 35 & 0.1 & 185.4 & 176.4 & 608.5 \\
\hline Oil & 65 & 35 & 0.085 & 256.6 & 244.2 & 842.7 \\
\hline Water & 65 & 35 & 0.077 & 312.7 & 296.4 & 1022.6 \\
\hline Air & 67 & 33 & 0.091 & 223.8 & 212.8 & 734.4 \\
\hline Oil & 67 & 33 & 0.089 & 234.06 & 222.6 & 768.1 \\
\hline Water & 67 & 33 & 0.085 & 256.6 & 244.2 & 842.7 \\
\hline Air & 70 & 30 & 0.097 & 197 & 187.3 & 646.1 \\
\hline Oil & 70 & 30 & 0.095 & 205.4 & 195.4 & 674.1 \\
\hline Water & 70 & 30 & 0.093 & 214.3 & 203.9 & 703.5 \\
\hline Air & 75 & 25 & 0.104 & 171.4 & 163.2 & 563.2 \\
\hline Oil & 75 & 25 & 0.1 & 185.4 & 176.4 & 608.5 \\
\hline Water & 75 & 25 & 0.098 & 193 & 183.7 & 633.7 \\
\hline Air & 100 & 0 & 0.32 & 18.1 & - & - \\
\hline Oil & 100 & 0 & 0.215 & 40.1 & - & - \\
\hline Water & 100 & 0 & 0.2 & 46.3 & -- & -- \\
\hline
\end{tabular}




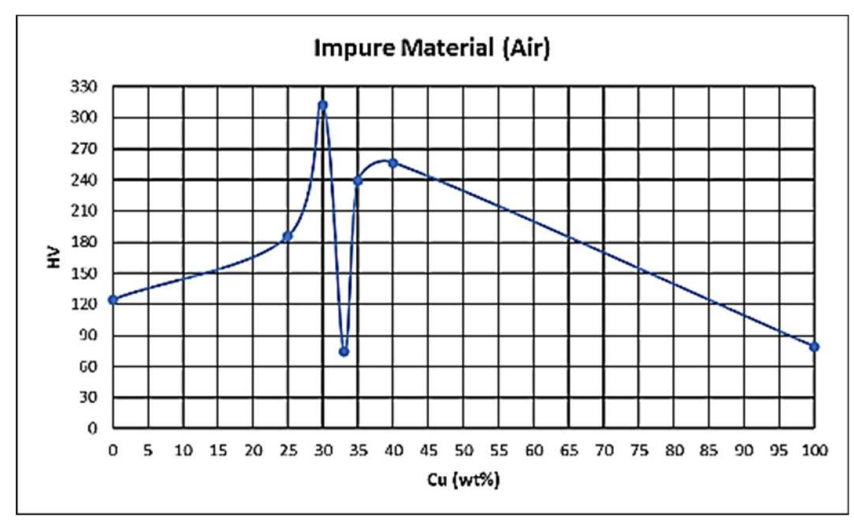

(a)

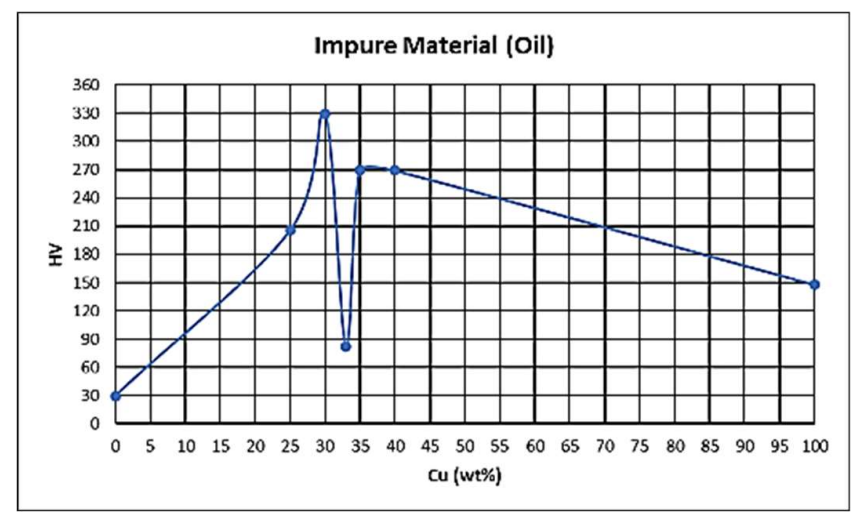

(b)

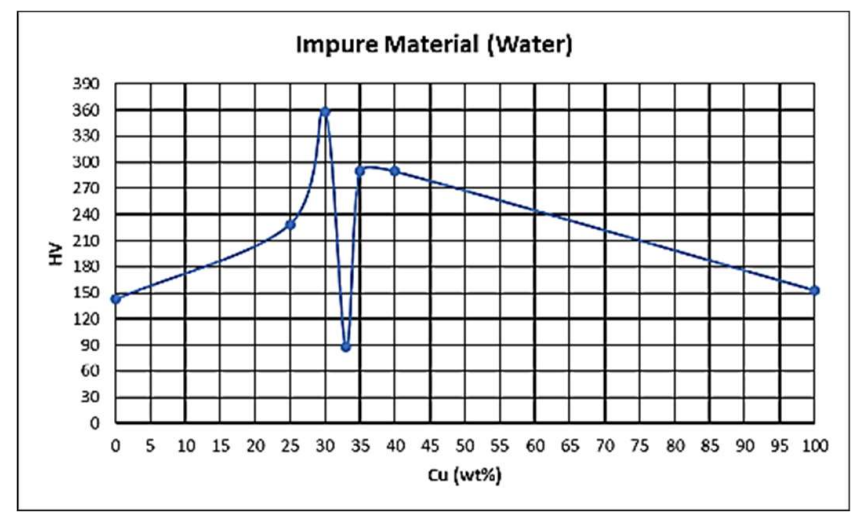

(c)

Figure 4: Relationships of the Al-Cu cast alloys impure group between the HV measurements and $\mathrm{Cu}$ wights(100-Al wights) for the quench type (a) air, (b) oil, and (c) water 


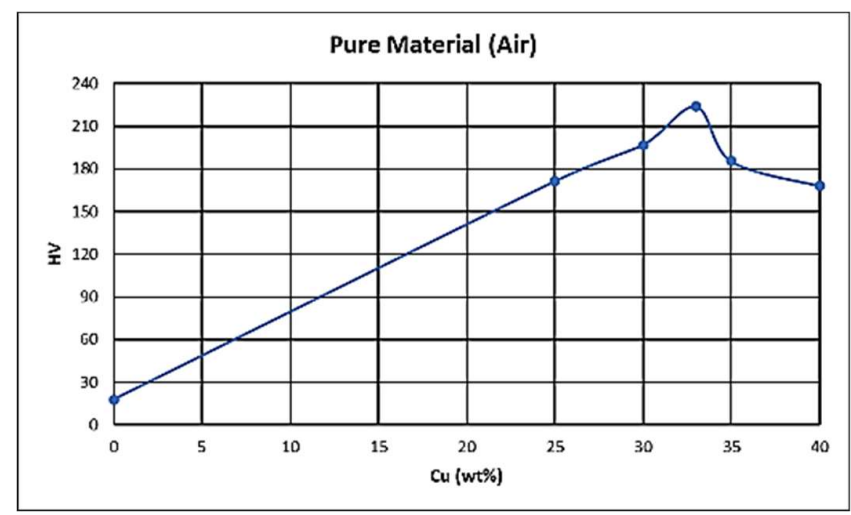

(a)

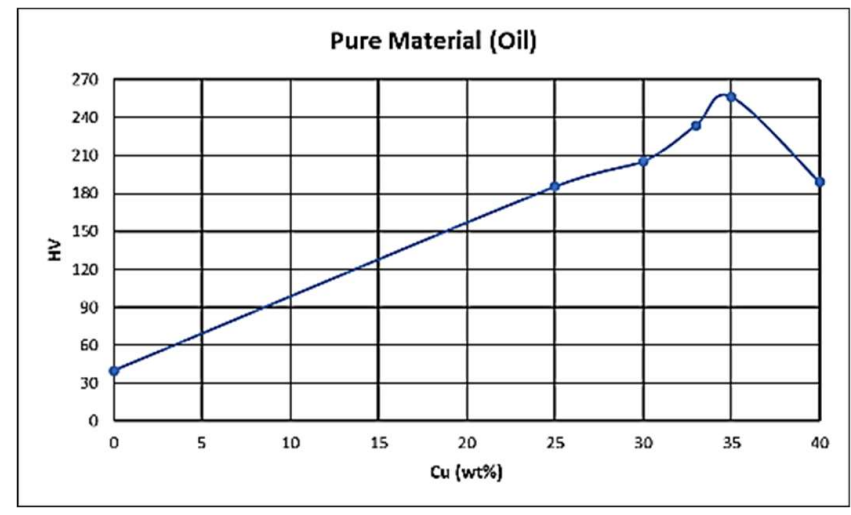

(b)

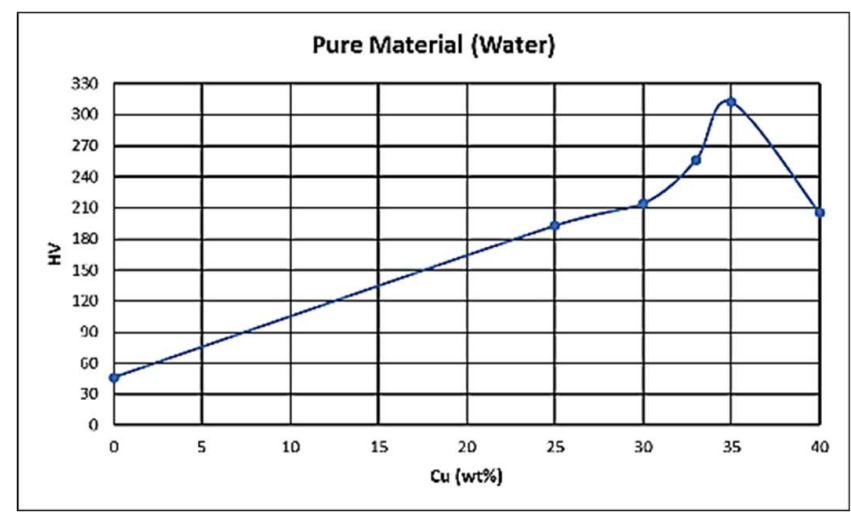

(c)

Figure 5: Relationships of the Al-Cu cast alloys pure group between the HV measurements and $\mathrm{Cu}$ wights(100-Al wights) for the quench type (a) air, (b) oil, and (c) water 
Another main issue that is worth to be highlighted is that the impure cast alloys are less affected by the quenched conditions of air, oil and water than the pure cast alloys. This is also expectable because the pure cast alloys are sensible to the quenched conditions. However, the influences of different quenched conditions to the pure cast alloys are slight not significant. With more explanation, the highest measurement value is when $\mathrm{Cu}$ weight equal to $33 \%$ after quenching by air and it is when $\mathrm{Cu}$ weight equal to $35 \%$ after quenching by the other conditions (oil and water). This is due to the sensitivity of pure cast alloys to the different quenched conditions, where using air provides slow quenching time than oil and water.

The suggested processing steps in this paper can be considered to be worthy as other suggested processing steps in [23-83].

\section{Conclusions}

This paper offered a comprehensive study for impure and pure casts of $\mathrm{Al}$ and $\mathrm{Cu}$. It consisted of multiple steps, these are: collecting $\mathrm{Al}$ and $\mathrm{Cu}$ materials, grouping them into impure and pure, changing percentages of mixed $\mathrm{Al}$ and $\mathrm{Cu}$ weights, establishing multiple $\mathrm{Al}-\mathrm{Cu}$ cast alloys, treating them by heating inside an electric furnace, chopping the cast alloys, repeating the heat treatments followed by quenching with various conditions (oil, water or air), applying effective measurements (HV, HB and TS) and considering multiple essential points (eutectic point, two nearest points around it and two far points of hypoeutectoid and hypereutectoid), and extensively discussing and comparing the essential outcomes. 
First of all, the measured HV, HB and ST values for the pure cast alloys are more smoother than the impure cast alloys. This is because of the influencing of other embedded elements in the impure cast alloys.

The results were attained such promises, reasonable and interesting outcomes. The HV, HB and ST measurements yielded that the eutectic point has obtained very low values and the point which is located near from the eutectic has achieved very high values for the Al- $\mathrm{Cu}$ cast alloys impure group in all quenched conditions. On the other hand, the same employed measurements exhibited that the eutectic or a point near from it has obtained very high values and the hypoeutectoid point which is located far from the eutectic has achieved very high values for the $\mathrm{Al}-\mathrm{Cu}$ cast alloys pure group in all quenched conditions.

The contradictory between the performances of impure and pure cast alloys can be explained. The impure cast alloys are influenced by other embedded elements, whereas, the pure cast alloys are not affected by such elements. Moreover, the pure cast alloys are more sensible to the quenched conditions of air, oil and water than the impure cast alloys.

\section{References}

[1] J. Osten et al., "Development of Precipitation Hardening Parameters for High Strength Alloy AA 7068," Materials (Basel)., vol. 13, no. 4, 2020, doi: 10.3390/ma13040918.

[2] Non-Ferrous Founders' Society and Copper Development Association, "Copper Casting Alloys," 7014-0009, p. 111, 1994, [Online]. Available: https://www.copper.org/publications/pub_list/pdf/7014.pdf\%0Ahttp://www.worldc at.org/title/copper-casting-alloys/oclc/31469090\&referer=brief_results. 
[3] P. Fathi, M. Mohammadi, X. Duan, and A. M. Nasiri, "A comparative study on corrosion and microstructure of direct metal laser sintered AlSi10Mg_200C and die cast A360.1 aluminum," J. Mater. Process. Technol., vol. 259, 2018, doi: 10.1016/j.jmatprotec.2018.04.013.

[4] J. G. Kaufman, Properties and Characteristic of Aluminum and Aluminum Alloys and Measuring the Effects of Fire Exposure on the Properties of Aluminium Alloys. 2016.

[5] J. Rosalie and L. Bourgeois, "Growth ledges on silver-segregated $\theta^{\prime}(\mathrm{A} 12 \mathrm{Cu})$ precipitates," in Minerals, Metals and Materials Series, 2016, no. 210869, doi: 10.1007/978-3-319-65136-1_64.

[6] J. Tao, "Surface composition and corrosion behavior of an Al-Cu alloy," p. 180, 2016, [Online]. Available: https://tel.archives-ouvertes.fr/tel-01412882/document.

[7] H. Wang et al., "Microstructure, corrosion behavior and mechanical properties of a non-isothermal ageing treated cast $\mathrm{Al}-4.5 \mathrm{Cu}-3.5 \mathrm{Zn}-0.5 \mathrm{Mg}$ alloy," Mater. Res. Express, vol. 7, no. 1, p. 16547, 2019, doi: 10.1088/2053-1591/ab638a.

[8] “Published in: Scripta Materialia 54 (2006) 287-291,” Scr. Mater., vol. 54, pp. 287$291,2006$.

[9] X. H. An et al., "High strength and utilizable ductility of bulk ultrafine-grained CuAl alloys," Appl. Phys. Lett., vol. 92, no. 20, 2008, doi: 10.1063/1.2936306.

[10]M. Li, H. Wang, Z. Wei, and Z. Zhu, "Effect of returns on microstructure and mechanical properties of AL-Cu based alloys," China Foundry, vol. 7, no. 1, pp. 37$42,2010$.

[11]X. H. An et al., "The influence of stacking fault energy on the mechanical properties of nanostructured $\mathrm{Cu}$ and $\mathrm{Cu}-\mathrm{Al}$ alloys processed by high-pressure torsion," Scr. 
Mater., vol. 64, no. 10, pp. 954-957, 2011, doi: 10.1016/j.scriptamat.2011.01.041.

[12]Y. Hao, X. X. Wu, X. Y. San, S. Li, and X. K. Zhu, “The influence of stacking fault energy on compression test of $\mathrm{Cu}$ and $\mathrm{Cu}-\mathrm{Al}$ alloys," Procedia Eng., vol. 36, no. December 2012, pp. 307-315, 2012, doi: 10.1016/j.proeng.2012.03.045.

[13] W. A. Ayoola, S. O. Adeosun, O. S. Sanni, and A. Oyetunji, "Effect of casting mould on mechanical properties of 6063 aluminum alloy," J. Eng. Sci. Technol., vol. 7, no. 1, pp. 89-96, 2012.

[14]N. A. Belov, A. O. Mikhailina, A. N. Alabin, and O. O. Stolyarova, "Theoretical and Experimental Study of the $\mathrm{Al}-\mathrm{Cu}-\mathrm{Si}-\mathrm{Sn}$ Phase Diagram in the Range of Aluminum Alloys," Met. Sci. Heat Treat., vol. 58, no. 3-4, pp. 195-201, 2016, doi: 10.1007/s11041-016-9988-5.

[15] S. Madhusudan, M. M. M. Sarcar, and N. B. R. M. Rao, "Mechanical properties of Aluminum-Copper(p) composite metallic materials," J. Appl. Res. Technol., vol. 14, no. 5, pp. 293-299, 2016, doi: 10.1016/j.jart.2016.05.009.

[16]Z. Stošić et al., "Effects of composition and thermal treatment of Cu-Al-Zn alloys with low content of $\mathrm{Al}$ on their shape-memory properties," Mater. Res., vol. 20, no. 5, pp. 1425-1431, 2017, doi: 10.1590/1980-5373-MR-2017-0153.

[17] S. Bansal, S. Rana, and M. Sharma, "Synthesis and Characterization of Al-Cu-Mg Aluminium Alloys and Study the Effect of Deformation and Aging on their Properties," Synth. Charact. Al-Cu-Mg Alum. Alloy. Study Eff. Deform. Aging their Prop., vol. 4, no. 8, pp. 112-116, 2017, doi: 10.17148/IARJSET.2017.4816.

[18] S. Bozorgi and K. Anders, "MECHANICAL PROPERTIES OF HIGH COPPER CONTAINING Al-Cu-Si CAST ALLOYS AT ELEVATED TEMPERATURE," 2018. 
[19]M. N. Su and B. Young, "Material properties of normal and high strength aluminium alloys at elevated temperatures," Thin-Walled Struct., vol. 137, pp. 463-471, 2019, doi: 10.1016/j.tws.2019.01.012.

[20] A. Soni and R. K. Mandloi, "Mechanical and Tribological Behaviour of Artificially Aged ( T6 ) Al-Zn-Mg-Cu Alloy,” no. 3, pp. 1988-1993, 2020, doi: 10.35940/ijitee.C9121.019320.

[21]H. Puga, "Casting and forming of advanced aluminum alloys," Metals (Basel)., vol. 10, no. 4, pp. 2-4, 2020, doi: 10.3390/met10040494.

[22]W. D. Callister and D. G. Rethwisch, Fundamentals of Materials Science and Engineering, An Integrated Approach, 3rd ed. 2008 John Wiley \& Sons, Inc., 2007.

[23] Raiq Rafi Omar Al-Nima, "Manufacturing Al-Cu and Al-Cu-Mg Alloys with Studying Some of their Mechanical Properties", Master thesis, Department of Physics, College of Science, University of Mosul, Iraq, 2021.

[24] Raiq Rafi Omar Al-Nima and Mahmood Ahmed Ahmod Al-Juboori, "Manufacturing Al-Cu-Mg Alloys and Studying Various Mechanical Properties," Advances in Mechanics, Vol. 9, No. 3, pp. 291-311, 2021.

[25] N. K. Asmel, R. R. Al-Nima, F. I. Mohammed, A. M. Al Saadi, and A. A. Ganiyu, "Forecasting Effluent Turbidity and $\mathrm{pH}$ In Jar Test Using Radial Basis Neural Network", Towards a Sustainable Water Future: Proceedings of Oman's International Conference on Water Engineering and Management of Water Resources, ICE Publishing, pp. 361-370, 2021.

[26] A. A. Ismael, S. J. Suleiman, R. R. O. Al-Nima, and N. Al-Ansari, "Predicting the discharge coefficient of oblique cylindrical weir using neural network techniques", Arabian Journal of Geosciences, Vol. 14, No. 1670, 2021. 
https://doi.org/10.1007/s12517-021-07911-9

[27] Sarah Othman Ali, Raid Rafi Omar Al-Nima, and Emad Ahmed Mohammed, “Communication Establishment Based on Authenticating Earprints", International Journal of Future Generation Communication and Networking, Vol. 14, No. 1, pp. 3242-3264, 2021.

[28] Mohammed Abdulzahra Ahmed Al-Dulaimi, Raid Rafi Omar Al-Nima, and Mohammad Riyadh R. Sharba, "Encrypting Communication Transmission Messages by Utilizing Multi-Layer Perception Neural Network", INFORMATICA JOURNAL, Vol. 32, No. 4, pp. 21-39, 2021.

[29] Shaima Miqdad Mohamed Najeeb, Raid Rafi Omar Al-Nima, and Mohand Lokman Al-Dabag, "Reinforced Deep Learning for Verifying Finger Veins", International Journal of Online and Biomedical Engineering (iJOE), Vol. 17, No. 07, pp. 19-26, July 2021. https://doi.org/10.3991/ijoe.v17i07.24655

[30] Moatasem Yaseen Al-Ridha, Ammar Sameer Anaz, Raid Rafi Omar Al-Nima, "Expecting Confirmed and Death Cases of COVID-19 in Iraq by Utilizing Backpropagation Neural Network", Bulletin of Electrical Engineering and Informatics, Vol. 10, No. 4, pp. 2137-2143, August 2021.

[31] Raid Rafi Omar Al-Nima, Tingting Han, Saadoon Awad Mohammed Al-Sumaidaee, Taolue Chen, and Wai Lok Woo, "Robustness and performance of Deep Reinforcement Learning”, Elsevier, Applied Soft Computing, Vol. 105, 2021. https://doi.org/10.1016/j.asoc.2021.107295

[32] Abdulsattar M. Ibrahim, Abdulrahman K. Eesee, and Raid Rafi Omar Al-Nima, "Deep Fingerprint Classification Network", TELKOMNIKA Telecommunication, Computing, Electronics and Control, Vol. 19, No. 3, 2021. 
[33] Lubab H. Albak, Raid Rafi Omar Al-Nima, and Arwa Hamid Salih, "Palm print Verification Based Deep Learning", TELKOMNIKA Telecommunication, Computing, Electronics and Control, Vol. 19, No. 3, 2021.

[34] Raid R. Al-Nima, Fawaz S. Abdullah, and Ali N. Hamoodi, "Design a Technology Based on the Fusion of Genetic Algorithm, Neural Network and Fuzzy Logic", arXiv:2102.08035, 2021.

[35] Mohand Lokman Al-dabag, Haider Th. Salim ALRikabi, and Raid Rafi Omar AlNima, “Anticipating Atrial Fibrillation Signal Using Efficient Algorithm", International Journal of Online and Biomedical Engineering (iJOE), Vol. 17, No. 02, pp. 106-120, 2021.

[36] Arwa Hamed Salih Hamdany, Raid Rafi Omar Al-Nima, and Lubab H. Albak, “Translating cuneiform symbols using artificial neural network", TELKOMNIKA Telecommunication, Computing, Electronics and Control, Vol. 19, No. 2, pp. 438 443, 2021.

DOI: 10.12928/TELKOMNIKA.v19i2.16134

[37] Raid Rafi Omar Al-Nima, Muhammed Khidr Jarjes, Ahmed Waled Kasim, and Sinan S. Mohammed Sheet, "Human Identification using Local Binary Patterns for Finger Outer Knuckle", In 2020 IEEE 8th Conference on Systems, Process and Control (ICSPC), Melaka, Malaysia, pp. 7-12, 2020.

[38] Ammar Sameer Anaz, Raid Rafi Omar Al-Nima, and Moatasem Yaseen Al-Ridha, “Multi-Encryptions System Based on Autoencoder Deep Learning Network", Solid State Technology, Vol. 63, Issue 6, 2020.

[39] Wai Lok Woo, Bin Gao, Raid Rafi Omar Al-Nima, and Wing-Kuen Ling, "Development of Conversational Artificial Intelligence for Pandemic Healthcare 
Query Support”, International Journal of Automation, Artificial Intelligence and Machine Learning, Vol. 1, Issue 1, 2020.

[40] Marwa MohamedSheet AL-Hatab, Raid Rafi Omar Al-Nima, Ilaria Marcantoni, Camillo Porcaro, and Laura Burattini, "Classifying Various Brain Activities by Exploiting Deep Learning Techniques and Genetic Algorithm Fusion Method”, TEST Engineering \& Management, Vol. 83, pp. 3035-3052, 2020.

[41] Marwa MohamedSheet AL-Hatab, Raid Rafi Omar Al-Nima, Ilaria Marcantoni, Camillo Porcaro, and Laura Burattini, "Comparison Study Between Three Axis Views of Vision, Motor and Pre-Frontal Brain Activities", Journal of Critical Reviews, Vol. 7, Issue 5, pp. 2598-2607, 2020. doi:10.31838/jcr.07.05.430

[42] Raid Rafi Omar Al-Nima, Saba Qasim Hasan, and Sahar Esmail, "Exploiting the Deep Learning with Fingerphotos to Recognize People”, International Journal of Advanced Science and Technology, Vol. 29, No. 7, pp. 13035 - 13046, 2020.

[43] Musab T. S. Al-Kaltakchi, Raid Rafi Omar Al-Nima, Mahmood Alfathe, and Mohammed A. M. Abdullah, "Speaker Verification Using Cosine Distance Scoring with i-vector Approach", in 2020 International Conference on Computer Science and Software Engineering (CSASE), IEEE, 2020.

[44] Raid R. O. Al-Nima, Tingting Han, Taolue Chen, Satnam Dlay, and Jonathon Chambers, "Finger Texture Biometric Characteristic: a Survey", arXiv preprint arXiv:2006.04193, 2020.

[45] Musab T. S. Al-Kaltakchi, Raid R. O. Al-Nima, and Mohammed A. M. Abdullah, "Comparisons of extreme learning machine and backpropagation-based i-vector approach for speaker identification", Turkish Journal of Electrical Engineering \& 
Computer Sciences, The Scientific and Technological Research Council of Turkey, Vol. 38, No. 3, pp. 1236-1245, 2020.

[46] Mabroukah M. A. Abuqadumah, Musab A. M. Ali, and Raid R. O. Al-Nima, "Personal Authentication Application Using Deep Learning Neural Network", in 16th IEEE International Colloquium on Signal Processing \& its Applications (CSPA), Langkawi, Malaysia, pp. 186-190, 2020.

[47] Lubab H. Albak, Arwa Hamed, and Raid Rafi Omar Al-Nima, "Design Security System based on Arduino", TEST Engineering \& Management, The Mattingley Publishing Co., Inc., Vol. 82, pp. 3341-3346, January-February 2020.

[48] R. R. O. Al-Nima, N. A. Al-Obaidy, and L. A. Al-Hbeti, "Segmenting Finger Inner Surface for the Purpose of Human Recognition", 2nd International Conference on Engineering Technology and its Applications (IICETA), IEEE, pp. 105-110, 2019.

[49] Arwa Hamid Salih Hamdany, Lubab H. Albak, and Raid Rafi Omar Al-Nima, "Wireless Waiter Robot", TEST Engineering \& Management, The Mattingley Publishing Co., Inc., Vol. 81, pp. 2486-2494, November-December 2019.

[50] Musab T. S. Al-Kaltakchi, Raid Rafi Omar Al-Nima, Mohammed A. M. Abdullah, and Hikmat N. Abdullah, "Thorough Evaluation of Timit Database Speaker Identification Performance Under Noise With and Without the G.712 Type Handset”, Springer, International Journal of Speech Technology, Vol. 22, No. 3, pp. 851-863, 2019.

DOI 10.1007/s10772-019-09630-9

[51] Raid Rafi Omar Al-Nima, Moatasem Yaseen Al-Ridha, and Farqad Hamid Abdulraheem, "Regenerating Face Images from Multi-Spectral Palm Images Using 
Multiple Fusion Methods", TELKOMNIKA Telecommunication, Computing, Electronics and Control, Vol. 17, No. 6, pp. 3120-3129, December 2019.

DOI: 10.12928/TELKOMNIKA.v17i6.12857

[52] Raid Rafi Omar Al-Nima, Farqad Hamid Abdulraheem, and Moatasem Yaseen AlRidha, "Using Hand-Dorsal Images to Reproduce Face Images by Applying Back propagation and Cascade-Forward Neural Networks", $2^{\text {nd }}$ International Conference on Electrical, Communication, Computer, Power and Control Engineering (ICECCPCE19), IEEE, Mosul, Iraq, 13-14 February, 2019.

[53] Moatasem Yaseen Al-Ridha, Raid Rafi Omar Al-Nima, and Ammar Sameer Anaz, “Adaptive Neuro-Fuzzy Inference System for Controlling a Steam Valve”, in 2019 IEEE 9th International Conference on System Engineering and Technology (ICSET), Shah Alam, Malaysia, 2019.

[54] R. R. O. Al-Nima, T. Han, and T. Chen, "Road Tracking Using Deep Reinforcement Learning for Self-driving Car Applications”, In: R. Burduk, M. Kurzynski and M. Wozniak (eds), Progress in Computer Recognition Systems, CORES 2019, Advances in Intelligent Systems and Computing, Vol. 977, Springer, Cham, 2020.

[55] R. R. Omar, T. Han, S. A. M. Al-Sumaidaee, and T. Chen, "Deep Finger Texture Learning for Verifying People”, IET Biometrics, Vol. 8, Issue 1, 2019.

[56] R. R. O. Al-Nima, M. Al-Kaltakchi, S. Al-Sumaidaee, S. Dlay, W. Woo, T. Han, and J. Chambers, "Personal Verification Based on Multi-Spectral Finger Texture Lighting Images”, IET Signal Processing, Vol. 12, Issue 9, 2018.

[57] M. T. Al-Kaltakchi, R. R. Omar, H. N. Abdullah, T. Han, and J. A. Chambers, “Finger Texture Verification Systems Based on Multiple Spectrum Lighting Sensors 
With Four Fusion Levels", Iraqi Journal of Information \& Communications Technology, Vol. 1, Issue 3, 2018.

[58] Raid Rafi Omar Al-Nima, "Signal Processing and Machine Learning Techniques for Human Verification Based on Finger Textures", PhD thesis, School of Engineering, Newcastle University, UK, 2017.

[59] M. A. M. Abdullah, R. R. Al-Nima, S. S. Dlay, W. L. Woo, and J. A. Chambers, “Cross-spectral Iris Matching for Surveillance Applications”, Springer, Surveillance in Action Technologies for Civilian, Military and Cyber Surveillance, Chapter 5, 2017.

[60] R. R. O. Al-Nima, M. A. M. Abdullah, M. T. S. Al-Kaltakchi, S. S. Dlay, W. L. Woo, and J. A. Chambers, "Finger Texture Biometric Verification Exploiting Multiscale Sobel Angles Local Binary Pattern and Score-based Fusion”, Elsevier, Digital Signal Processing, Vol. 70, 2017, Pages 178-189.

https://doi.org/10.1016/j.dsp.2017.08.002.

[61] S. A. M. Al-Sumaidaee, M. A. M. Abdullah, R. R. O. Al-Nima, S. S. Dlay, and J. A. Chambers, "Multi-gradient Features and Elongated Quinary Pattern Encoding for Image-based Facial Expression Recognition”, Elsevier, Pattern Recognition, Vol. 71, pp. $249-263,2017$.

[62] R. R. O. Al-Nima, S. S. Dlay, W. L. Woo, and J. A. Chambers, "Efficient Finger Segmentation Robust to Hand Alignment in Imaging with Application to Human Verification", 5th IEEE International Workshop on Biometrics and Forensics (IWBF), 2017. 
[63] R. R. O. Al-Nima, S. S. Dlay, S. A. M. Al-Sumaidaee, W. L. Woo, and J. A. Chambers, "Robust Feature Extraction and Salvage Schemes for Finger Texture Based Biometrics", in IET Biometrics, Vol. 6, No. 2, pp. 43-52, 2017. doi: 10.1049/iet-bmt.2016.0090

[64] R. R. O. Al-Nima, S. S. Dlay, W. L. Woo, and J. A. Chambers, “A Novel Biometric Approach to Generate ROC Curve from the Probabilistic Neural Network", in 24th IEEE Signal Processing and Communication Application Conference (SIU), Zonguldak, Turkey, 2016, pp. 141-144.

[65] R. Al-Nima, S. Dlay, W. Woo, and J. Chambers, "Human Authentication With Finger Textures Based on Image Feature Enhancement", in 2nd IET International Conference on Intelligent Signal Processing (ISP), 2015.

[66] F. M. Shehab, R. R. O. Al-Nima, and R. Y. Sedik, "Estimating Reference EvapoTranspiration in Mosul (Iraq) Using Cascade Neural Networks", Eng. \& Tech. Journal, Vol. 32, No. Part (A) 9, 2014.

[67] R. R. Al-Nima, S. Dlay, and W. Woo, “A new approach to predicting physical biometrics from behavioural biometrics", International Journal of Computer, Information, Systems and Control Engineering, Vol. 8, No. 11, 2014.

[68] Raid Rafi Al-Nima, "Steganography for Text in Video File Using Radial Neural Network", 3rd International Scientific Conference, Foundation of Technical Education, Technical Education, Najaf, 2013.

[69] J. H. Al-Khalidy and R. R. Al-Nima, "Breast Tumor Classification Using SVM", Tikrit Journal of Engineering Sciences, Vol. 20, No. 5, 2013.

[70] D. A. B. Keryou, R. R. Al-Nima, and R. N. Wadie, “Design of Beam-Columns Using Artificial Neural Networks", Eng. \& Tech. Journal, Vol. 30, No. 16, 2012. 
[71] R. R. Al-Nima, "Human Authentication With Earprint for Secure Telephone System", Iraqi Journal of Computers, Communications, Control and Systems Engineering IJCCCE, Vol. 12, No. 2, 2012.

[72] R. R. Omar and F. H. Abd Al-Raheem, "Steganography of Gray-Scale Images on Video File", The Islamic College University Journal, The Islamic College University, Alnajaf Alashraf, No. 14, 2011.

[73] R. R. Al-Nima, "Design a Biometric Identification System Based on the Fusion of Hand Geometry and Backhand Patterns", Iraqi Journal of Statistical Science, Vol. $17,2010$.

[74] R. R. Al-Nima, M. L., and S. Q. Hassan, "Data Encryption Using Backpropagation Neural Network", Tikrit Journal of Pure Science, Vol. 15, No. 2, 2010.

[75] O. A. AL-Badrani and R. R. AL-Nima, "Recognition Between Eudiscoaster and Heliodiscoaster Using Competitive Neural Network", Iraqi Journal of Earth Sciences, Vol. 10, No. 2, pp. 97 - 110, 2010.

[76] R. R. Al-Nima, A. N. Hamed, and R. Y. Srdeeq, "Multiple Data Type Encryption Using Genetic Neural Network", Tikrit Journal of Eng. Sciences, Vol.17, No. 2, pp. $51-57,2010$.

[77] R. S. Al-jawadi and R. R. Al-Nima, "Hybrid Genetic Algorithm With Neural Network in English Language Cipher", AL-Rafidain Journal of Computer Sciences and Mathematics, Vol. 7, No. 3, pp. 77-90, 2010.

[78] R. R. Al-Nima and F. S. Mustafa, "Face Recognition Using Invariant Moments Features", The Scientific Journal, College of Science, Tikrit University, Salahadeein, Iraq, Vol. 14, No. 2, 2009. 
[79] M. R. Khalil, M. S. Majeed, and R. R. Omar, "Personal Identification With Iris Patterns", AL-Rafidain Journal of Computer Sciences and Mathematics, College of Computer Sciences and Math / University of Mosul / Iraq, Vol. 6, No. 1, 2009.

[80] R. R. Al-Nima and S. Kasim, "Picture Recognition by Using Linear Associative Memory Neural Network", Tikrit Journal of Pure Science, Vol. 13, No. 3, 2008.

[81] R. R. Al-Nima, "Image Processing for Iris Extraction", 10th Scientific Conference for Foundation of Technical Education-Baghdad, 2007.

[82] Raid Rafi Omar Al-Nima, "Personal Identification Based on Iris Patterns", Master thesis, Technical Engineering College of Mosul, Iraq, 2006.

[83] M. R. Khalil, M. S. Majeed, and R. R. Omar, "Personal Identification With Iris Patterns", The First Scientific Conference for Information Technology, College of Computer Sciences and Math / University of Mosul / Iraq, Vol. 6, No. 1, 2009. 